\title{
Análise de assunto e mapas conceituais:semelhanças nos processos
}

Maria Rosemary Rodrigues

Mestre em Ciência da Informação pelo Programa de Pós-Graduação em Ciência da Informação da Universidade Estadual de Londrina. Londrina. Paraná.

Brígida Maria Nogueira Cervantes

Doutora em Ciência da Informação pela Universidade Estadual Paulista - Campus Marília. Professora Adjunta do Programa de Pós-Graduação em Ciência da Informação da Universidade Estadual de Londrina. Paraná.

http://dx.doi.org/10.1590/1981-5344/2423

Aborda o Tratamento Temático da Informação com destaque para Mapas Conceituais e a atividade Análise de Assunto como contribuições para Organização e Representação do Conhecimento. $O$ objetivo foi de verificar semelhanças entre os Mapas Conceituais e o processo de Tratamento Temático da Informação, mais especificamente na atividade de Análise de Assunto. A metodologia caracterizou-se como estudo exploratório e descritivo, além do delineamento da pesquisa bibliográfica. Com abordagem qualitativa, a análise de dados fundamentou-se em Becker (2007), que se utilizou da Lógica - processo de ir e vir. Os principais resultados demonstram que os Mapas Conceituais e a atividade de Análise de Assunto assemelham-se enquanto processo em relação à descrição temática do conteúdo do documento. Considera-se que, tanto a Análise de Assunto, quanto os Mapas Conceituais se assemelham por possuírem características comuns em todo o processo e por meio de suas intenções. Conclui-se que os Mapas Conceituais 
podem colaborar com o campo da ORC, pela razão das etapas de Extração e Tradução de Conceitos estarem presentes na Análise de Assunto e também no processo de construção de Mapas Conceituais.

Palavras-chave: Tratamento temático da informação. Análise de assunto. Mapas conceituais.

\section{Subject analysis and concept maps: similarities in processes}

The present work deals with the Subject Treatment of Information with emphasis on Concept Maps and the Subject Analysis activity as contributions to the Organization and Knowledge Representation. The objective was to verify similarities between Concept Maps and the STI process, specifically in the Subject Analysis activity. The methodology was characterized as exploratory and descriptive study, in addition to the design of the literature research. Using a qualitative approach, data analysis was based on Becker (2007), which was used Logic - "come and go" process. The main results show that the concept maps and the Subject Analysis activity are similar as a process in relation to the thematic description of the content of the document. It was considered that both the Subject Analysis as the Concept Maps resemble because they shared similar characteristics, in all process and through their interactions. It follows that the Concept Maps can collaborate with the field of ORC, by reason of the steps of Extraction and Concepts Translation attend the Subject Analysis and also in the Concept Maps construction process.

Keywords: Subject treatment of information. Subject analysis. Concept maps.

Recebido em 12.05.2015 Aceito em 03.11.2015 


\section{Introdução}

O artigo apresenta uma visão geral sobre Tratamento Temático da Informação e posteriormente a respeito da Análise de Assunto e Mapas Conceituais, fundamentada na Organização e Representação do Conhecimento. O procedimento metodológico caracterizou-se como exploratório e descritivo, com delineamento da pesquisa bibliográfica, porque se exploraram, por meio de leitura teórico-metodológica, contribuições sobre os temas para estabelecer uma visão geral para conhecer, analisar, descrever o que foi observado e registrado. O objetivo que conduziu este artigo foi de verificar semelhanças entre os Mapas Conceituais e o processo de Tratamento Temático da Informação, mais especificamente na atividade de Análise de Assunto, por meio de uma avaliação mais detalhada durante a construção do referencial teóricometodológico, cuja análise de dados fundamentou-se em Becker (2007), que se utilizou da Lógica - processo de ir e vir.

A justificativa para este estudo foi inserir os Mapas Conceituais como processo na Organização e Representação do Conhecimento, com o intuito de aprimorar o Tratamento Temático da Informação e propiciar um subsídio intelectual por meio de analogias, com base nos autores Naves (2001) e Dias e Naves $(2007$; 2013) com o processo de construção de Mapas Conceituais, fundamentado em Novak (2000).

Neste contexto, buscaram-se contribuições para a Ciência da Informação e mais especificamente para a Biblioteconomia, no que se refere à perspectiva de desenvolvimento em Unidades de Informação, por haver várias atividades que envolvem a cognição, representam uma estrutura de conceitos para serem descritos e comunicados. Além de representarem "[...] o raciocínio humano dando visibilidade ao pensamento estruturando as ideias viabilizando a emergência da subjetividade" (NEVES, 2012, p. 46).

Dessa forma, a necessidade em contribuir com a literatura a respeito dessa temática se sobressai, isso porque, há instrumentos pedagógicos que podem vir a se apresentar como alternativas viáveis para referenciar os processos de representação, a fim de possibilitar a disseminação e a recuperação da informação.

\section{Tratamento temático da informação (TTI)}

O Tratamento Temático da Informação (TTI) está conectado com a Organização e Representação do Conhecimento (ORC) em razão dos processos em operações específicas, isto é, o tratamento temático identifica, processa e disponibiliza o conteúdo do documento. Isso porque o acúmulo de campos de conhecimento e a interdisciplinaridade vêm promovendo o surgimento de documentos com conteúdos mais complexos e, por causa disso, menciona-se sobre a necessidade do profissional que 
lida com o tratamento da informação dominar técnicas para organização de informações, procurando torná-las acessíveis aos usuários.

O T.T.I. como termo amplo refere-se à análise, descrição e representação do conteúdo de documentos (GUIMARÃES, 2009; GUIMARÃES; SALES; GRÁCIO, 2012). Para complementar, de acordo com Barité (2001, tradução nossa), ao se realizar as etapas de identificar, processar e disponibilizar o conteúdo do documento, o T.T.I. propicia condições para efetuar as operações de representação e acesso à informação.

O processo metodológico do T.T.I., de acordo com Kobashi (1994), representa o conteúdo de documentos e é necessário realizar a análise (um trabalho intelectual, por meio da leitura documental, extrair os conceitos que melhor representam o conteúdo do documento e, para isso, realiza-se a decomposição de todo o conteúdo em partes que constituem o documento) (DAL'EVEDOVE, 2010; DAL'EVEDOVE; FUJITA, 2013); a síntese (etapa que determina 0 assunto por meio dos conceitos selecionados, ou seja, ao escolher e fixar os conceitos ou palavras-chave que traduzem o conteúdo do documento) (DAL'EVEDOVE, 2010; DAL'EVEDOVE; FUJITA, 2013); e a representação (construída a partir do processo de condensação do texto) (DAL'EVEDOVE, 2010; DAL'EVEDOVE; FUJITA, 2013). Portanto, as fases de análise e síntese desconstroem o texto para que a operação da representação reconstrua-o de maneira a facilitar a recuperação temática da informação.

Ulterior, apresenta-se a Análise de Assunto, para em seguida abordar conceitualização e as etapas das fases da análise e a tradução de assuntos, enquanto características subjetivas nas operações do processo de T.T.I.

\section{Análise de assunto}

No que diz respeito à operação T.T.I., a atividade de Análise de Assunto manifesta o entendimento dos significados dos documentos e o acesso à informação conforme a necessidade do usuário. Desse modo, o entendimento dos significados dos documentos refere-se ao desenvolvimento de teorias para analisar assuntos das áreas do conhecimento e à construção de instrumentos e métodos para representar a informação contida no documento (CERVANTES, 2006). O acesso à informação refere-se à abordagem cognitiva do usuário, isto é, o seu entendimento sobre algum assunto de alguma área do conhecimento (CERVANTES, 2006).

Com base nos autores Dias e Naves (2007; 2013), analisou-se o contexto sobre a Análise de Assunto como processo do T.T.I. para estabelecer uma visão mais próxima a do processo de construção de Mapas Conceituais, vindo a estabelecer as semelhanças entre as referidas áreas. 
Segundo os autores Dias e Naves (2007; 2013), a Análise de Assunto define-se como um conjunto de procedimentos com o intuito de expressar o conteúdo do documento, com o escopo de representar a informação de forma condensada para consulta e para a armazenagem, de maneira a facilitar a recuperação da informação.

O que sustenta as atividades da Análise de Assunto é o conteúdo do documento, por conseguinte apresenta seu sentido estrito como:

Conjunto de operaciones intelectuales que conducen a representar el contenido del documento de modo distinto al original, com los objetivos últimos de contribuir ao control documental y al servicio a la comunidade científica, dada la vocación pragmática y de servicio que le caracteriza (GARRIDO ARILLA, 1999, p. 183).

Desse modo, trata-se de um conjunto de operações que se realizam no conteúdo do documento, para facilitar sua recuperação.

Os autores Naves (2001) e Dias e Naves (2007; 2013) consideram que para alcançar a palavra-chave são necessários o Indexador, a Indexação e a Análise de Assunto.

- INDEXADOR - não possui uma definição conceitual, visto que na América do Norte e Grã-Bretanha é aceito na graduação de Biblioteconomia como o profissional que tem papel importante na recuperação da informação, e, pela literatura inglesa e americana, o indexador elabora índices, faz tratamento de assunto, descreve e traduz os termos para uma linguagem específica. O profissional da informação que realiza a Indexação e a Análise de Assunto denomina-se Indexador, além disso, possui fatores de influência, sendo o principal deles o fator humano, isso porque pensa, abstrai, interpreta e define o assunto sob o seu ponto de vista, ou seja, a influência profissional ocorre por meio de fatores próprio ao funcionamento da mente humana, sendo eles subjetivos, já que dependem das inclinações pessoais e afetivas, do conhecimento prévio e da formação e experiência da área em que se está indexando.

- A INDEXAÇÃO - é a ação que identifica e descreve o conteúdo de documentos. É o processo básico para recuperar a informação por meio da atividade de Análise de Assunto.

- ANÁLISE DE ASSUNTO - define-se como o procedimento para compreender e interpretar o conteúdo informacional de documentos. Tem por autoras principais a professora espanhola Maria Pinto Molina e Claire Beghtol, que é canadense. A Análise de Assunto possui várias denominações e tem por objetivo representar a informação de forma condensada para consulta e armazenagem (PINTO MOLINA, 1993, tradução nossa). Seu processo é composto por duas etapas. A primeira se refere à extração de conceitos para representar o conteúdo de 
documentos; a segunda etapa consiste na Tradução dos termos da Linguagem Natural (LN) para termos chamados Linguagem de Indexação. Do ponto de vista do indexador, a Análise de Assunto inicia-se pela leitura do texto, após realiza-se a extração de conceitos, depois se faz a representação, em que se define a $L N$, e por fim executa-se a tradução por meio da Linguagem Documentária (LD), que passa a ser denominadas palavras-chave, descritores de assunto, cabeçalhos de assunto, termos de indexação ou enunciados. Essas fases passam pela interferência de fatores linguístico, cognitivo e lógico, proporcionando um caráter interdisciplinar. Na dimensão do T.T.I., a atividade Análise de Assunto possui aspectos interdependentes que acontecem durante o seu processo, que engloba o conceito, o assunto e o contexto.

- CONCEITO - o conceito é definido como unidades do conhecimento identificadas por enunciados verdadeiros e podem ser representadas pelo conceito geral, que é esclarecido pela classe de algo, ou pelo conceito individual, explicado por algo individual. Para um melhor entendimento apresenta-se um exemplo: Bibliotecas referem-se a um conceito geral, e no que diz respeito a conceito individual, Biblioteca Tradicional, Biblioteca Infantil, Biblioteca Universitária, entre outras. Os conceitos podem ser representados de forma Lexical (verbal - palavra ou fala) e de forma Não - Lexical (não verbal - escrita ou símbolos). Ainda para a formação de conceitos utilizam-se os processos mentais inseparáveis compostos por Análise (consiste em separar em partes, bem como decompor); Síntese (equivale em recompor para um todo); Abstração (operação de isolar ou separar o todo sem sair do contexto para identificar o específico 'acidental' do geral 'genérico'); e Generalização (identifica-se como uma categorização, isto é, dentro da mesma classe a inserção de elementos essenciais, gerais, universais). Entretanto esses processos dependem de fatores, tais como: a percepção (início do trabalho mental), a emoção (sentimentos para a ação), a atitude (o que predispõe para a ação) e a linguagem (sistema de símbolos verbais para comunicar-se).

- ASSUNTO - refere-se a um termo ambíguo, tanto em relação ao seu uso, quanto a sua terminologia. Apesar disso, neste contexto, a palavra assunto é entendida como sinônimo de ideia. Assunto pode ser denominado objetivo, quando os conceitos existem independentes da consciência humana, ou subjetivo, quando o conceito está na mente das pessoas. Também é utilizado para explicar a ideia principal, visto que o assunto responde a questão: do que se trata? $\mathrm{E}$ a ideia principal questiona: o que o autor quer dizer no texto? No entanto, isso depende da visão de cada leitor, por meio da leitura que realiza do texto. Ademais, nos tipos de texto narrativo, a ideia principal tem a ver com os acontecimentos e a interpretação. Já em texto informativo, o conceito e as regras vêm a ser relevantes. Por causa das diferentes formas de concepções de assunto, tem-se a indexação, que acontece pela atividade Análise de Assunto. 
CONTEXTO - O contexto tem a intenção de verificar a produção em determinado momento. É realizado por meio da leitura técnica que nada mais é do que a descrição contextual (autor, data, entre outros) e a informação contextual (espaço para recuperar a informação e a importância para o significado do termo). Assim, entende-se que os aspectos interdependentes que acontecem no processo da leitura técnica geram um assunto, que se refere a um produto de extração de conceitos em algum contexto e estão sempre juntos na indexação. Por outro lado, alguns autores apontam para "A função principal que a indexação deveria ter é de busca por conhecimento" (DIAS; NAVES, 2013, p. 62).

- MAPAS CONCEITUAIS - introduzido nesta temática, o Mapa Conceitual vem a auxiliar a primeira etapa da Análise de Assunto, ou seja, a extração de conceitos, bem como organizar e representar conceitos. Conforme a autora citada no texto, Lima (2004), a construção de Mapa Conceitual acontece por meio do processo que possui as etapas: seleciona, ordena, agrupa, arranja e link/proposição os conceitos. Também sugere o programa Cmap Tools como ferramenta para auxiliar na construção de um mapa conceitual.

Para representar a estrutura conceitual da junção dos textos Naves (2001) e Dias e Naves $(2007 ; 2013)$ e proporcionar uma visão completa do assunto, elaborou-se o Mapa Conceitual a seguir. Para efeito deste estudo, na próxima seção, destacam-se os Mapas Conceituais. 
Figura 1 - Mapa Conceitual da junção dos textos Naves (2001), Dias e Naves $(2007 ; 2013)$

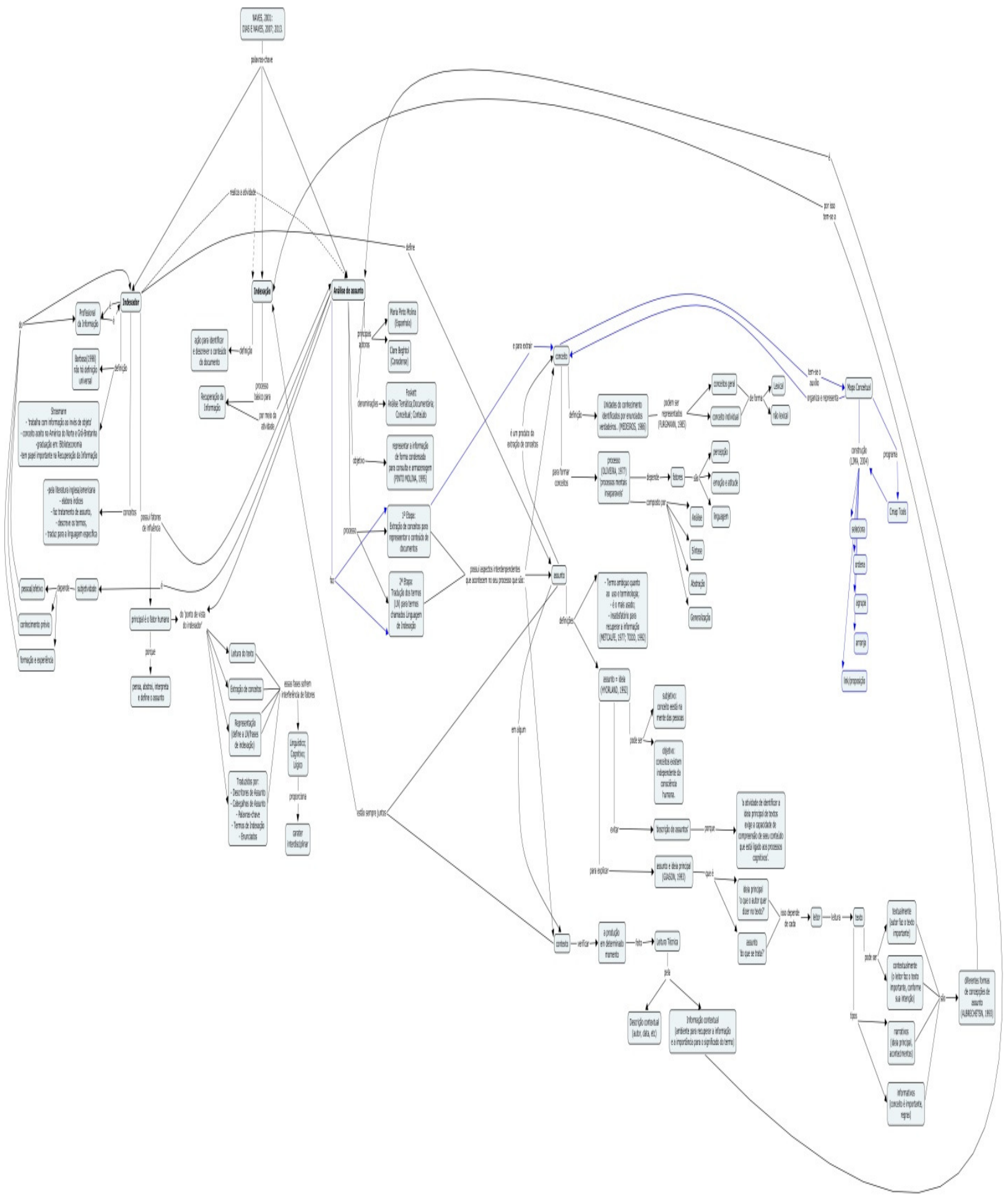

Fonte: RODRIGUES (2014, p. 151) fundamentado em NAVES (2001) e NAVES e DIAS (2007; 2013). 


\section{Mapas conceituais}

O mapa conceitual surgiu de uma pesquisa do professor Joseph Novak, na Universidade de Cornell, em Nova York, na década de 1970, em uma investigação com crianças sobre o que "sabiam acerca de um domínio do conhecimento, antes e depois da instrução" (NOVAK, 2000, p. 27), que teve como finalidade algo que representasse o conhecimento dessas crianças. Complementando, criou os mapas conceituais como instrumento para fazer visível o tipo de aprendizagem adquirida (ROVIRA, 2005, tradução nossa). Novak (2000), Novak e Cañas (2008), Moreiro González et al. (2004) referem-se aos mapas conceituais como ferramentas gráficas para organizar e representar o conhecimento, ou seja, trata-se de uma ferramenta, na forma de gráfico, fundamentada na aprendizagem significativa formulada por David Ausubel para buscar a representação do conhecimento armazenado na estrutura cognitiva de um indivíduo, uma vez que esta aprendizagem acontece a partir da assimilação da relação entre o conhecimento prévio e o novo conhecimento, "[...] formando novas conexões entre os conceitos" (COLLA; MEDEIROS; ANDRADE, 2003, p. 154).

Novak desenvolveu os mapas conceituais para pôr em prática as ideias de David Ausubel sobre Aprendizagem Significativa (ONTORIA et al., 2005). A Aprendizagem Significativa está subordinada a quatro aspectos básicos de acordo com Souza e Buruchovith (2010a; 2010b): Diferenciação Progressiva (refere-se à hierarquização dos conceitos, dispondo-os dos mais gerais para os mais inclusos), Reconciliação Integrativa (trata-se das relações entre os conceitos estruturados de forma hierárquica, indicando a compreensão mais ampla das semelhanças e diferenças), Organização Sequencial (processo de compreensão) e a Consolidação (é o que se sabe, ou seja, a aprendizagem significativa).

Há também a Aprendizagem Mecânica, que se infere a memorização de curto prazo, pois não faz relações entre o novo conhecimento e o conhecimento prévio. Esse processo pode vir a facilitar e ser o início para a Aprendizagem Significativa.

Conforme definições, a começar por Moreira (2012), os mapas conceituais constituem-se uma técnica para cumprir vários objetivos, porque representam relações entre os conceitos de uma área, disciplina ou assunto. Nesse sentido, os mapas conceituais definem-se ora como um instrumento ou como uma ferramenta, ora como estratégia, ora como método ou técnica ou recurso esquemático, consoante autores como Moreira e Rosa (1986); Novak (2000); Ontoria et al. (1999, 2005); Rovira (2005, tradução nossa); Belluzzo (2007); Marques (2008); Dutra, Fagundes e Cañas (2009). Para Novak (2000), os mapas conceituais são instrumentos para trabalhar o significado. Em sua visão, para entender o conhecimento é necessário dialogar e compartilhar informações. Pode ser aplicável ou adaptado em diversas situações, conforme os objetivos que se queira alcançar. 
Segundo Moreira e Rosa (1986); Guarido e Moraes (2002); Colla, Medeiros e Andrade (2003); Belluzzo (2007) e Marques (2008), a representação dos mapas conceituais é como diagramas que demonstram a organização do conhecimento, ou qualquer outra informação. Moreira (2012) considera que são diagramas de significados com relações expressivas e com hierarquias conceituais, pois não buscam classificar conceitos, e sim os relacionar e hierarquizar.

Observam-se os mapas conceituais por meio de definição descritiva, ou seja, é composto por conceitos que se referem a "[...] regularidade percebida em eventos ou objetos, ou registros de eventos ou objetos, designados por um rótulo" (NOVAK; CAÑAS, 2008, p. 1) e se posicionam dentro de círculos ou caixas, além das palavras ou pequenas frases de ligação, que se posicionam nas linhas que fazem a relação entre um conceito e outro, formando uma proposição, sendo essa sua característica particular (NOVAK, 2000; MARQUES, 2008), conforme a figura a seguir, que demonstra os elementos de um mapa conceitual.

Figura 2 - Elementos de um Mapa Conceitual

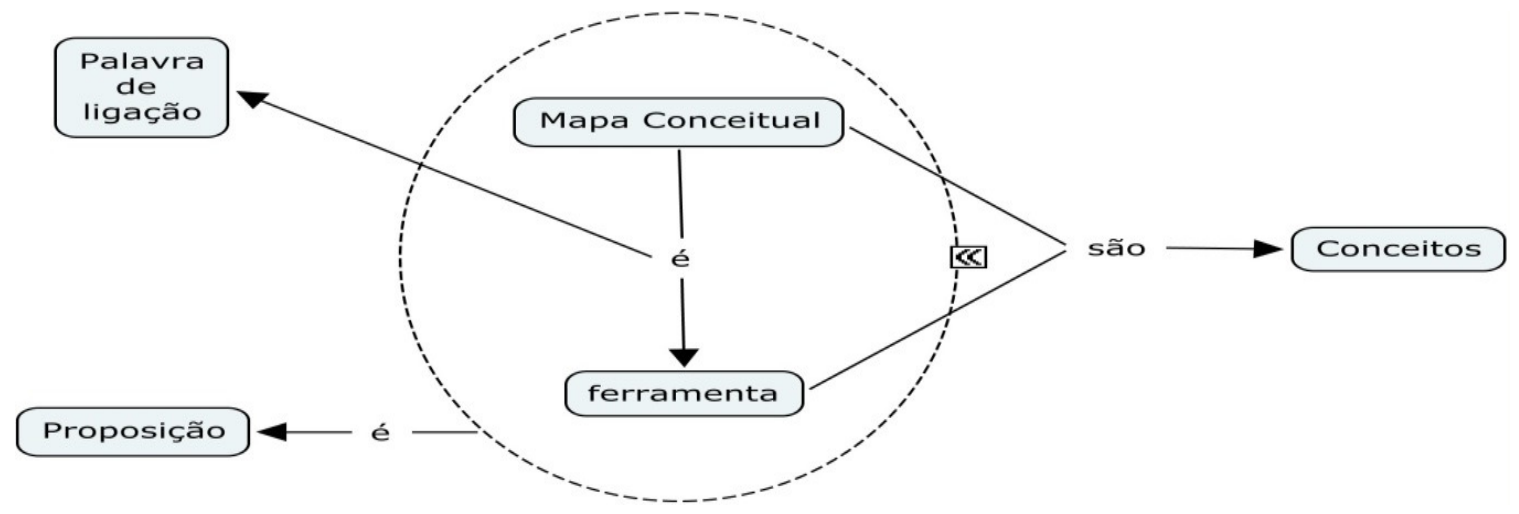

Fonte: RODRIGUES (2014, p. 64) fundamentado em PRATS GARCIA (2013, p. 45).

As tipologias dos Mapas Conceituais podem ser: Teia de Aranha ( $O$ conceito geral fica no centro e os específicos ao redor e se distanciando do centro como Teia de Aranha. Entretanto, não promove relações entre os conceitos) (TAVARES, 2007); Fluxograma ("[...] uma visão esquemática, cheia de direções preferenciais indicadas por setas", ou seja, "[...] uma sequência de operações") (MOREIRA, 2006, p. 92-93); Flowchart (Organiza a informação em formato linear, semelhante à estrutura de um livro (KINDS OF CONCEPT MAPS, 2002); e Hierárquico (Apresenta a informação do geral para o específico e proporciona relação entre os conceitos) (TAVARES, 2007), o que permite entender melhor a estrutura da informação, isso porque o processo e a organização do conhecimento na memória fundamentam-se na Aprendizagem Significativa e também porque os mapas conceituais trabalham com os conceitos e suas relações. Assim, "para o cientista da informação, que lida com Análise de Assunto [...] pode tornar-se um instrumento importante para ajudá-lo a entender 
e lidar com estruturas informacionais" (LIMA, 2004, p. 137), visto que o seu formato gráfico pode auxiliá-lo no processo de análise-sínteserepresentação para aprimorar a ORC.

O uso dos mapas conceituais refere-se como estratégia para o ensino, aprendizagem e como ferramenta avaliativa, quando usado para desenvolver o intelecto do aluno, e como estratégia para o planejamento curricular, quando utilizado para a apresentação, de maneira sucinta, dos princípios e dos conceitos chave a serem selecionados. Também pode ser aplicado na representação do conhecimento (ROVIRA, 2005, tradução nossa).

Os mapas conceituais, segundo Lima (2004), podem ter outros propósitos, tais como: suscitar ideias por meio do processo de brain storming (tempestade de ideias), ao realizar uma coleta e análise das informações e ao estipular relações para construir outros conceitos; esquematizar uma estrutura mais organizada de textos, documentos, hipertextos/hipermídia e sites da Web; elaborar e disseminar informações no modelo gráfico; colaborar no processo de aprendizagem agregando conhecimentos novos e antigos estabelecidos a algum domínio do conhecimento; contribuir para a identificação de algo não compreendido, pois assim é possível discernir e confrontar ideias opostas.

O mapa conceitual representa o conhecimento definido por conceitos e a sua construção deve ser iniciada a partir do domínio de conhecimento de cada pessoa, ou seja, essa construção "[...] não é realizada de forma artificial, mas sim levando em consideração o conhecimento do mundo a que se pertence e como a ele se responde" (CERVANTES, 2006, p. 30). Nesse sentido, ainda segundo a autora citada acima, "Para a organização de um domínio, desde a sua representação até a sua recuperação, estudam-se, primeiramente, os conceitos que compõem esse campo do conhecimento e as relações que se estabelecem entre eles" (CERVANTES, 2006, p. 26).

Assim, fundamentado de forma simplificada nos autores Novak (2000); Lima (2004); Moreira (2006); Belluzzo (2007); Moreiro González (2011); Ontoria et al. (1999, 2005); Marques (2008); Prats Garcia (2013), apresenta o processo para elaboração de um mapa conceitual constituído de seis fases:

Quadro 1 - Processo para a construção de Mapa Conceitual

Processo para a construção de Mapa Conceitual

1) Identificar o tema ou a pergunta de enfoque que vai se representar;

2) Verificar os conceitos;

3) Ordenar os conceitos por meio de lista;

4) Agrupar e arranjar os conceitos que são demonstrados a partir de palavras ou símbolos (no topo) e inseridos exemplos característicos atrelados aos conceitos (na base);

5) Estabelecer os links ou proposições, ou seja, as conexões dos conceitos por meio de 
linhas e as nomeações por meio de palavra ou pequena frase;

6) Rever a estrutura do mapa conceitual e refazê-lo, se necessário.

Fonte: Elaborado pelas autoras fundamentado em RODRIGUES (2014).

Os mapas conceituais podem ser desenvolvidos de diferentes maneiras para o mesmo conjunto de conceitos e também mudarão conforme os entendimentos dos relacionamentos entre os conceitos forem se alterando.

Os primeiros programas com finalidade específica de se construir mapas conceituais surgiram a partir da década de 1980. Mas, para efeito deste estudo, citaremos o Cmap Tools, que se refere a um programa desenvolvido pelo Institute for Human and Machine Cognition (IHMC), instituto com fins filantrópicos que faz parte de um sistema universitário da Flórida. O Cmap Tools foi concebido sob a coordenação de Aberto J. Cañas, juntamente com a colaboração de Joseph D. Novak (PRATS GARCIA, 2013, tradução nossa). Trata-se de software de download gratuito de mapas conceituais em diversos sistemas (BELLUZZO, 2007; MAGALHÃES; RIO, 2008; PRATS GARCIA, 2013, tradução nossa), traduzido em 17 idiomas (PRATS GARCIA, 2013, tradução nossa), que permite construir, navegar, compartilhar de maneira individual ou colaborativa. O uso do software Cmap Tools oferece a permissão de inserir recursos, tais como: links, textos, figuras, imagens, vídeos, sons, e Uniform Resource Locator (URL), vindo a promover a construção de mapas conceituais.

\section{Procedimentos metodológicos}

O desenvolvimento deste estudo teórico-metodológico para verificar semelhanças entre os Mapas Conceituais e o processo de Tratamento Temático da Informação, mais especificamente na atividade de Análise de Assunto, caracterizou-se como exploratório e descritivo, com delineamento da pesquisa bibliográfica, em que se exploraram, por meio de leitura teórico-metodológica, contribuições sobre os temas para estabelecer uma visão geral ou próxima (GIL, 2006) para conhecer, analisar, descrever o que foi observado e registrado. A abordagem foi essencialmente qualitativa, o que permitiu a interpretação e compreensão dos dados coletados em determinado contexto para contribuir na produção de conhecimento.

Já a análise de dados realizou-se por meio do processo de análise, no qual se utilizou a Lógica - "[...] um processo constante de ir e vir [...]" (BECKER, 2007, p. 189), em razão de que ao analisar algum conteúdo de documento é preciso retornar para dar mais uma olhada. Isso porque "[...] manipular o que sabemos segundo algum conjunto de regras de tal modo que as manipulações produzam coisas novas" (BECKER, 2007, p. 188). 
Para um melhor entendimento e com a intenção de destacar a análise de 'ir e vir' de Becker (2007), realizou-se uma analogia entre um exemplo aristotélico, 'Os homens são mortais, Sócrates era um homem, portanto Sócrates era mortal', com uma das definições sobre Mapas Conceituais à luz da obra de Novak (2000): 'Ferramentas organizam e representam o conhecimento, Mapas conceituais é uma ferramenta, portanto Mapas Conceituais organizam e representam o conhecimento'.

Por assim dizer, o que é dito numa premissa maior afirma uma verdade geral já admitida, ou seja, 'ferramentas organizam e representam o conhecimento'. Já na premissa menor, declara-se um fato particular também admitido, ou seja, 'Mapas Conceituais é uma ferramenta' e como conclusão tem-se a declaração que supostamente decorre do fato de a premissa menor ser um caso especial da verdade geral expressa na premissa maior, estando, portanto, incluída nela ou abrangida por ela, ou seja, 'Mapas Conceituais organizam e representam o conhecimento'.

Essa análise nos remete a ideia de que a premissa maior está tão enraizada na experiência diária das pessoas que não exigirá demonstração ou raciocínio. Entretanto, tornar a conexão entre a premissa maior e menor mais clara provoca uma necessidade de uma análise embutida em investigar os usos e significados de termos. Pautado na literatura, elaboraram-se as premissas para explicar e justificar a semelhança entre as atividades de análise de assunto e o processo de construção de Mapas Conceituais. Portanto, pode-se vir a encontrar casos dados como interessantes (quando os Mapas Conceituais são vistos pela primeira vez ou praticados uma vez ou outra) ou de rotina (quando os Mapas Conceituais fazem parte do cotidiano).

Segundo Becker (2007), esse estudo pode trazer contribuição teórica, apresentando um novo olhar para a dimensão investigada, pois de forma geral não se presta atenção a todas as coisas que se está estudando.

\section{Análise e resultados}

A analogia das obras dos autores Naves (2001) e Dias e Naves (2007; 2013) com os Mapas Conceituais possibilitou reflexões teóricometodológicas, que apontaram para semelhanças comuns em todo o processo.

Primeiramente, percebeu-se que o Indexador, ou seja, o profissional da informação pode vir a construir um Mapa Conceitual, isto porque a aproximação com a Indexação é que tanto um quanto o outro identifica e descreve o conteúdo de documentos.

Já a aproximação entre a Análise de Assunto e o Mapa Conceitual pressupõe um procedimento para compreender e interpretar o conteúdo informacional de documentos para representar a informação de forma condensada por meio do processo de extração de conceitos e por meio da Tradução dos termos. Assim, segundo Rodrigues (2011, p. 60), "os mapas 
conceituais podem ser usados na organização e também na análise do conteúdo, $[\ldots]$ como um recurso didático diferenciado de representar a informação da forma textual".

Outra semelhança percebida foi que tanto os conceitos, bem como a linguagem, podem ser representados de forma Lexical (verbal - palavra ou fala) e de forma Não - Lexical (não verbal - escrita ou símbolos). "Entretanto, o mapa conceitual também se refere à ferramenta de representação de conceitos" (RODRIGUES, 2011, p. 14).

Com relação ao assunto, perceberam-se afinidades quando a palavra assunto é entendida como sinônimo de ideia. Por isso pode ser denominado de assunto objetivo, quando os conceitos existem independentes da consciência humana, isto é, a informação, que segundo Rodrigues (2011, p. 13) "A informação comunica alguma coisa a alguém por meio de símbolos, porém o significado depende do usuário". Também, "Ela é essencial e deve ser ordenada, estruturada e representada em diferenciado formato para chegar até o usuário" (RODRIGUES, 2011, p. $13 ; 2013$, p. 754). E, por outro modo, pode ser denominado de assunto subjetivo, quando o conceito está na mente das pessoas, isto é, o conhecimento, que segundo Rodrigues (2011, p. 13; 2013, p. 754) "é um conjunto de informações significativas e acumulativas advindas das experiências dos indivíduos, [...] as quais, quando compreendidas, provocam um novo conhecimento".

Também se verificou outra ligação quando se observou que a produção em determinado momento é realizada mediante a leitura técnica por meio da descrição contextual (autor, data, entre outros), pode-se dizer que a expressão de sentido é semelhante à Descrição Física. E, por meio da informação contextual (espaço para recuperar a informação e a importância para o significado do termo), pode-se dizer que a expressão de sentido é semelhante à Descrição Temática. Ademais, "a atividade de identificar a ideia principal de textos exige a capacidade de compreensão de seu conteúdo que está ligado aos processos cognitivos", o que também remete à Descrição Temática.

O Mapa Conceitual assemelhou-se à Análise de Assunto, uma vez que pode vir a auxiliar na primeira etapa, ou seja, na extração de conceitos, bem como na segunda etapa, em que se organizam e representam conceitos. Isso acontece porque, para realizar a atividade de Análise de Assunto, o ideal é que seja feito pelo leitor humano (profissional da informação, indexador), pois ele interpreta e define um assunto utilizando, de fato, os processos mentais inseparáveis (análise, síntese, abstração e generalização), que dependem de certos fatores (percepção, emoção, atitude e linguagem) para a formação de conceitos, que, por sua vez,

compreende a declaração verdadeira sobre algum objeto ou acontecimento e depende do conhecimento que se tem sobre assuntos, portanto, a representação mental que temos sobre 
cada palavra e seus variados usos a torna compreensiva. Por fim, o conceito é o significado da palavra relacionado no contexto, o que determina seu significado (RODRIGUES, 2011, p. 14),

por meio dos aspectos interdependentes (conceito, assunto e contexto) que acontecem durante o processo de Análise de Assunto.

A construção de Mapas Conceituais possui as etapas de selecionar, ordenar, agrupar, arranjar e link/proposição e é fundamentada na Aprendizagem Significativa que perpassa pelas fases de diferenciação progressiva, reconciliação integrativa, organização sequencial e consolidação, as quais também trabalham com conceitos. Nesse sentido, observou-se que a atividade de Análise de Assunto, bem como a construção de Mapas Conceituais, trabalha com o objeto que é o conhecimento e semelhantemente como ação, ambas referem-se a atividades intelectuais do conhecimento. Em síntese, a atividade de Análise de Assunto e a construção de Mapas Conceituais percorrem etapas que possuem conceitos com sentidos semelhantes, conforme o quadro a seguir.

No quadro a seguir uniram-se as fases da Análise de Assunto; os fatores dos quais dependem os processos mentais inseparáveis; o processo para formar conceitos; as etapas para a construção de Mapas Conceituais e as fases da Aprendizagem Significativa.

Quadro 2 - Analogia entre Análise de Assunto, fatores dos processos mentais, processo para formar conceitos, etapas dos Mapas Conceituais e Aprendizagem Significativa.

\begin{tabular}{|c|c|c|c|c|}
\hline $\begin{array}{c}\text { Análise } \\
\text { de Assunto }\end{array}$ & $\begin{array}{l}\text { Os fatores dos } \\
\text { quais } \\
\text { dependem os } \\
\text { processos } \\
\text { mentais } \\
\text { inseparáveis } \\
\end{array}$ & $\begin{array}{l}\text { O processo } \\
\text { para formar } \\
\text { conceitos }\end{array}$ & $\begin{array}{c}\text { Etapas para a } \\
\text { construção de } \\
\text { Mapas } \\
\text { Conceituais }\end{array}$ & $\begin{array}{c}\text { Fases da } \\
\text { Aprendizagem } \\
\text { Significativa }\end{array}$ \\
\hline \multirow{3}{*}{$\begin{array}{lr}\text { Leitura } & \text { do } \\
\text { documento e a } \\
\text { extração } & \text { dos } \\
\text { conceitos. } & \end{array}$} & $\begin{array}{l}\text { Percepção } \\
\text { (início do } \\
\text { trabalho } \\
\text { mental). }\end{array}$ & $\begin{array}{lr}\begin{array}{l}\text { Análise } \\
\text { (consiste }\end{array} \text { em } \\
\text { separar em } \\
\text { partes, bem } \\
\text { como } \\
\text { decompor). }\end{array}$ & $\begin{array}{l}\text { Seleciona } \\
\text { (separar, } \\
\text { eleger, } \\
\text { identificar). }\end{array}$ & $\begin{array}{l}\text { Diferenciação } \\
\text { Progressiva } \\
\text { (hierarquizar). }\end{array}$ \\
\hline & $\begin{array}{l}\text { Emoção } \\
\text { (sentimentos } \\
\text { para a ação) e } \\
\text { Atitude (o que } \\
\text { predispõe para } \\
\text { a ação). }\end{array}$ & $\begin{array}{l}\text { Síntese } \\
\text { (equivale em } \\
\text { recompor para } \\
\text { um todo). }\end{array}$ & $\begin{array}{l}\text { Ordena } \\
\text { Agrupa } \\
\text { (organizar, } \\
\text { associar). }\end{array}$ & $\begin{array}{l}\text { Reconciliação } \\
\text { Integrativa é } \\
\text { quando gera } \\
\text { um novo } \\
\text { conhecimento. }\end{array}$ \\
\hline & $\begin{array}{l}\text { Emoção } \\
\text { (sentimentos }\end{array}$ & $\begin{array}{l}\text { Abstração } \\
\text { (operação }\end{array}$ & $\begin{array}{l}\text { Arranja } \\
\text { (elaborar, }\end{array}$ & $\begin{array}{l}\text { Organização } \\
\text { Sequencial, isto }\end{array}$ \\
\hline
\end{tabular}




\begin{tabular}{|c|c|c|c|c|}
\hline $\begin{array}{l}\text { Tradução, isto } \\
\text { é, passar os } \\
\text { termos } \\
\text { Linguagem da } \\
\text { Natural para a } \\
\text { Linguagem } \\
\text { Documentária }\end{array}$ & $\begin{array}{l}\text { para a ação) e } \\
\text { Atitude (o que } \\
\text { predispõe para } \\
\text { a ação). }\end{array}$ & $\begin{array}{lr}\text { isolar } & \text { ou } \\
\text { separar o } & \text { todo } \\
\text { sem sair } & \text { do } \\
\text { contexto } & \text { para } \\
\text { identificar } & \text { o } \\
\text { específico } & \\
\text { 'acidental' } & \text { do } \\
\text { geral } & \\
\text { 'genérico'). } & \\
\end{array}$ & classificar). & $\begin{array}{lr}\text { é, realiza } & \text { a } \\
\text { categorização } & \\
\text { fazendo } & \text { uma } \\
\text { relação } & \text { de } \\
\text { conceitos } & \text { do } \\
\text { específico } & \text { para } \\
\text { o geral. } & \end{array}$ \\
\hline $\begin{array}{l}\text { (palavras- } \\
\text { chave; } \\
\text { descritores; } \\
\text { cabeçalhos de } \\
\text { assunto). }\end{array}$ & $\begin{array}{l}\text { Linguagem } \\
\text { (sistema de } \\
\text { símbolos } \\
\text { verbais para } \\
\text { comunicar-se). }\end{array}$ & $\begin{array}{l}\text { Generalização } \\
\text { (identifica-se } \\
\text { como uma } \\
\text { categorização, } \\
\text { isto é, dentro da } \\
\text { mesma classe a } \\
\text { inserção de } \\
\text { elementos } \\
\text { essenciais, } \\
\text { gerais, } \\
\text { universais). }\end{array}$ & $\begin{array}{l}\text { Link/Proposição } \\
\text { (afirmação, } \\
\text { enunciado, } \\
\text { unidade } \\
\text { semântica, } \\
\text { frase). }\end{array}$ & $\begin{array}{c}\text { Consolidação } \\
\text { ou } \\
\text { Aprendizagem } \\
\text { Significativa. }\end{array}$ \\
\hline
\end{tabular}

Fonte: RODRIGUES (2014, p.113).

Diante disso, as relações apresentadas acima se identificaram enquanto processo, porque as etapas entremeiam-se, suscitando a primeira e segunda fase da Análise de Assunto, uma vez que "'[...] servem para perceber as ideias chaves para centrar uma atividade [...], pois, 0 indivíduo constrói seu conhecimento relacionando vários elementos" (RODRIGUES, 2011, p. 64). E, também, porque se percebeu que "[...] a informação tem a sua existência atrelada aos sistemas de significado e que a operação nesse universo é necessária para a idenficação, análise, tratamento e disseminação" (CERVANTES, 2006, p. 20). Nesse sentido, os Mapas Conceituais podem vir a contribuir com a Análise de Assunto para que o processo contextualize o conceito de forma mais precisa, visto que tanto um quanto o outro possuem etapas comuns ou similares, ao realizar as atividades.

A seguir, o Mapa Conceitual sobre a junção dos textos de Naves (2001), Dias e Naves (2007; 2013): 
Figura 3 - Mapa Conceitual sobre a junção dos textos de Naves (2001) e Dias e Naves $(2007 ; 2013)$ em relação aos Mapas Conceituais

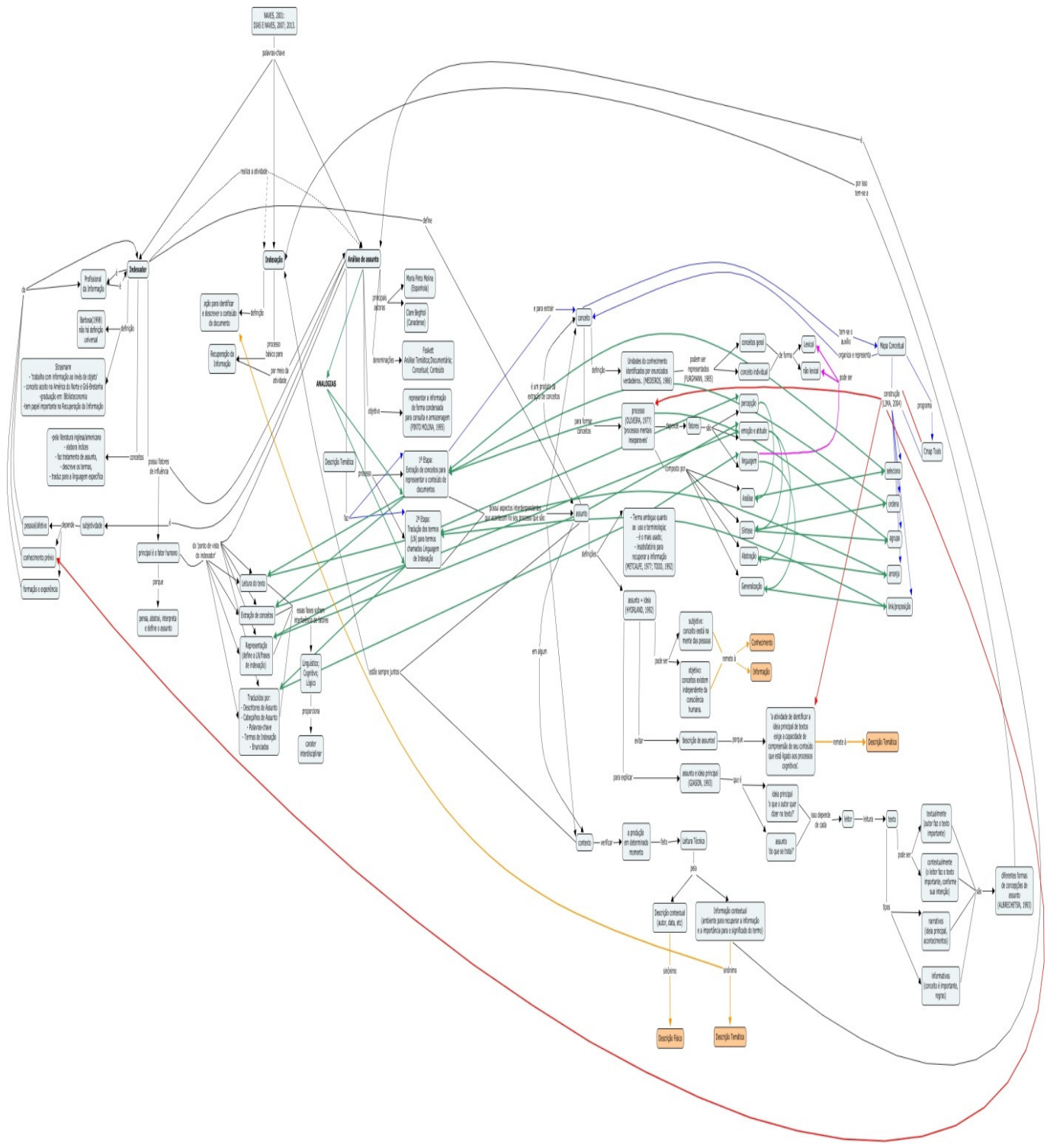

Fonte: RODRIGUES (2014, p.114) fundamentado em NAVES (2001) e DIAS e NAVES $(2007 ; 2013)$.

Como resultado, este estudo teórico-metodológico verificou semelhanças entre os Mapas Conceituais e o processo de Tratamento Temático da Informação, mais especificamente na atividade de Análise de Assunto, a princípio pelas definições, porque representam a organização do processo cognitivo de estruturas de conceitos. Em seguida pelo escopo dos processos, porque organizam e representam as estratégias metacognitiva de leitura para melhor entender e manipular a estrutura de informação, a fim de organizar e representar o conhecimento sobre algum 
assunto, estabelecendo as relações conceituais para recuperar a informação.

\section{Considerações finais}

Por meio deste estudo, novos processos relacionados à ORC vêm suscitando novas reflexões teórico-metodológicas, isso porque a diversidade e a quantidade demasiada de informações em Unidades de Informação apontam para o aprimoramento do T.T.I., mais especificamente na atividade Análise de Assunto.

Neste contexto, os Mapas Conceituais podem colaborar com o campo da ORC, ancorado especialmente nos autores Naves e Dias, porque, nos conteúdos estudados, verificaram-se semelhanças entre o processo de construção de Mapas Conceituais e a atividade Análise de Assunto no processo de análise - síntese - representação de pelos conceitos, principalmente pelos processos e pela representação, os quais se aproximam por meio de suas intenções e pela razão das etapas de Extração e Tradução de Conceitos estarem presentes nos dois processos.

Recomenda-se a inserção dos Mapas Conceituais em ORC, por se tratar de campo interdisciplinar, visto que nos tempos atuais utilizam-se novas tecnologias de informação e comunicação para o desenvolvimento teórico-metodológico.

Espera-se contribuir com a ORC ao analisar Mapas Conceituais, buscando propiciar o adensamento teórico-metodológico na área estudada, bem como auxiliar na promoção e na consolidação da Linha de Pesquisa Organização e Representação da Informação e do Conhecimento.

A sugestão para estudos posteriores volta-se especialmente sobre o aprofundamento de questões relacionadas à possibilidade de utilizar os Mapas Conceituais como processo no campo da ORC, a iniciar por meio de sua definição de organizar e representar o conhecimento para auxiliar nas estratégias de cognição dos profissionais da informação.

\section{Referências}

BARITÉ, M. Organizacion del conocimiento: un nuevo marco teoricoconceptual en bibliotecologia y documentacion. In: CARRARA, K. (Org.). Educação, universidade e pesquisa: textos completos do III simpósio em filosofia e ciência: paradigmas do conhecimento no final do milênio. Marília: Unesp-Marília-Publicações; São Paulo: FAPESP, 2001. p. 35-60.

BECKER, H. S. Segredos e truques da pesquisa. Rio de Janeiro: Jorge Zahar, 2007.

BELLUZZO, R. C. B. Construção de mapas: desenvolvendo competências em informação e comunicação. 2. ed. Bauru: Cá entre nós, 2007. 111 p. 
CERVANTES, B. M. N. Terminologia do processo de inteligência competitiva: estudo teórico e metodológico. Londrina: EDUEL, 2006. 152 p.

COLLA, A. L.; MEDEIROS, M. F. a de; ANDRADE, A. F.a de. Mapas conceituais: um procedimento metacognitivo de inclusão conceitual e o desafio hipermidiático. In: MEDEIROS, M. F. de; FARIA, E. T. (Orgs.). Educação à distância: cartografias pulsantes em movimento. Porto Alegre: EDIPUCRS, 2003. cap. 8. p. 151-173.

DAL' EVEDOVE, P. R.; FUJITA, S. L. M. Estudo sociocultural da comunidade discursiva do tratamento temático da informação em bibliotecas universitárias. Encontros Bibli [On-line], v.18, n. 36, p. 23-50, Enero/Abril 2013, $18 . \quad$ Disponível em: <http://www.redalyc.org/articulo.oa?id=14726166003>. Acesso em: 13 mar. 2014.

DAL' EVEDOVE, P. R. A perspectiva sóciocognitiva no tratamento temático da informação em bibliotecas universitárias: aspectos inerentes a percepção profissional. 2010. 300f. Dissertação (Mestre em Ciência da Informação) - Faculdade de Filosofia e Ciências, Universidade Estadual Paulista, Marília.

DIAS, E. W.; NAVES, M. L. Análise de assunto: teoria e prática. Brasília: Teshaurus, 2007. $116 \mathrm{p}$.

DIAS, E. W.; NAVES, M. L. Análise de assunto: teoria e prática. 2. ed. rev. Brasília: Briquet de Lemos, 2013. 115 p.

DUTRA, Í. M.; FAGUNDES, L. da C.; CAÑAS, A. J. Uma proposta de uso dos mapas conceituais para um paradigma construtivista da formação de professores a distância. Universidade Federal do Rio Grande do Sul (UFRGS). Programa de Pós-Graduação em Informática na Educação. Disponível em: <http://homer.nuted.edu.ufrgs.br/oficinas/criacao/mapas_prof.pdf>. Acesso em: 21 jun. 2009.

GARRIDO ARILLA, M. R. Teoria e historia de la catalogacíon de documentos. Madrid: Síntesis, 1999. cap. 3.

GIL, A. C. Métodos e técnicas de pesquisa social. 5. ed. São Paulo: Atlas, 2006. 206 p.

GUARIDO, M. D. M.; MORAES, J. B. E. de. Mapas conceituais: uma experiência de ensino no curso de Biblioteconomia da Unesp de Marília. In: ENCONTRO DE DIRETORES, 6., 2002, Londrina; ENCONTRO DE 
DOCENTES DE ESCOLAS DE BIBLIOTECONOMIA E CIÊNCIA DA INFORMAÇÃO DO MERCOSUL, 5., 2002, Londrina. Anais... Londrina: ABECIN, 2002.

GUIMARÃES, J. A. C. Abordagens teóricas de tratamento temático da informação (TTI): catalogação de assunto, indexação e análise documental $=$ Theoretical approaches on information subject treatment: subject cataloging, indexing and subject analysis. Ibersid. 2009. p. 105117.

Disponível

em:

<www.ibersid.eu/ojs/index.php/ibersid/article/download/3730/3491>.

Acesso em: 13 maio 2013.

GUIMARAES, J. A. C.; SALES, R.; GRACIO, M. C. C. A dimensão interdisciplinar da análise documental nos contextos brasileiro e espanhol no âmbito da organização do conhecimento. Datagramazero, Rio de Janeiro, v. 13, n. 6, 2012. Disponível em: <http://www.dgz.org.br/dez12/Art_07.htm>. Acesso em: 13 março 2014. KINDS of Concept Maps. University of Illinois ay Urbana-Champaign. College of Agricultural Consumer and Environmental Sciences. ACES 100 Discovery Class. The Mind Module. Ago. 2002. Disponível em <http://classes.aces.uiuc.edu/ACES100/Mind/c-m2.html>. Acesso em: 15 nov. 2013.

KOBASHI, N. Y. A elaboração de informações documentárias: em busca de uma metodologia. 1994. 195f. Tese (Doutorado em Ciências da Comunicação) - Escola de Comunicações e Artes, Universidade de São Paulo, São Paulo, 1994.

LIMA, G. A. B. de O. Mapa conceitual como ferramenta para organização do conhecimento em sistema de hipertextos e seus aspectos cognitivos. Perspcetivas em Ciência da Informação, v. 9, n. 2, 2004. Disponível em: <http://portaldeperiódicos.eci.ufmg.br/index.php/pci >. Acesso em: 15 nov. 2013.

MAGALHÃES, G. C.; RIOS, F. del. Mapas conceptuais online. In: CARVAlHO, A. A. A. (Org.). Manual de ferramentas da web 2.0 para professores. 2008. p. 211-232. Disponível em: <www.crie.minedu.pt/publico/web20/manual_web20-professores.pdf >. Acesso em: 5 fev. 2014.

MARQUES, A. M.de M. Utilização pedagógica de mapas mentais e de mapas conceptuais. 2008. Dissertação (Mestre em Expressão Gráfica, Cor e Imagem) - Universidade Aberta, Sintra, Portugal. Disponível em: <http://repositorioaberto.univ- 
ab.pt/handle/10400.2/1259?mode=full\&submit_simple

=Mostrar+registo+em+formato+completo $>$. Acesso em: 14 jul. 2009.

MOREIRA, M. A. Mapas conceituais como recurso instrucional e curricular. In: MOREIRA, M. A. A teoria da aprendizagem significativa e sua implantação em sala de aula. Brasília: Editora Universidade de Brasília, 2006. cap. 2.

MOREIRA, M. A. Mapas conceituais e aprendizagem significativa = Concept maps and meaningful learning. Instituto de Física - UFRGS. 2012. Disponível em: <www.if.ufrgs.br/ moreira/mapasport.pdf>. Acesso em: 20 ago. 2013.

MOREIRA, M. A.; ROSA, P. Mapas conceituais. Caderno Catarinense de Ensino de Física, Florianópolis, v. 3, n. 1, p. 17-25, abr.1986. Disponível em: <www.fsc.ufsc.br/cbef/port/03-1/artpdf/a3.pdf>. Acesso em: 19 jun. 2009.

MOREIRO GONZALEZ, J. et al. De los tesauros a los topic maps: nuevo estandar para la representación y la organización de la información. Encontros Bibli: Revista Eletrônica de Biblioteconomia e Ciência da Informação, Florianópolis, n. 18, p. 1-19, 20 sem. 2004. Disponível em: $<$ https://periodicos.ufsc.br/index.php/eb/article/view/1518-

2924.2004v9n18p1/5470>. Acesso em: 20 ago. 2013.

MOREIRO GONZÁLEZ, J. A. Linguagens documentárias e vocabulários semânticos para a web: elementos conceituais. Salvador: EDUFBA, 2011.

NEVES, D. A. de B. Representação temática da informação e mapas cognitivos: interações possíveis. Inf. \& Soc.: Est., João Pessoa, v.22, n. esp., 39-47, 2012. Disponível em: <http://www.ies.ufpb.br/ojs2/index.php/ies/article/view/13300/8208>.

Acesso em: 3 maio 2014.

NOVAK, J. D; CAÑAS, A. J. The theory underlying concept maps and how to construct and use them. Florida: Institute for Human and Machine Cognition, 2008. Disponível em: <http://cmap.ihmc.us/Publications/>. Acesso em: 20 jul. 2013.

NOVAK, J. D. Aprender criar e utilizar o conhecimento: mapas conceptuais como ferramentas de facilitação nas escolas e empresas = Learning, creating and using knowledge. Lisboa: Plátano Editora, 2000. 252 p.

ONTORIA, A. et al. Mapas conceptuais: uma técnica para aprender. 2. ed. Porto: Asa, 1999. 177 p. (Coleção Perspectivas Actuais/educação).

ONTORIA, A. et al. Mapas conceptuais: uma técnica para aprender. São Paulo: Loyola, 2005. 
PINTO MOLINA, M. Análisis documental: fundamentos y procedimientos. Madrid; EUDEMA, 1993.

PRATS GARCIA, E. La evaluación de mapas conceptuales: un caso práctico. 2013. 197f. Proyecto de Fin de Máster (Máster en Tecnología Educativa: e-learning y gestión del conocimiento) - Universitat de les Illes Balears, Espanha.

RODRIGUES, M. R. Organização e representação do conhecimento por meio de mapas conceituais. 2014. 154f. Dissertação (Mestre em Ciência da Informação) - Universidade Estadual de Londrina, Londrina. Disponível em: http://www.bibliotecadigital.uel.br/document/?code=vtls000194647. Acesso em: 5 mar. 2015.

RODRIGUES, M. R. Os mapas conceituais para a visualização de conceitos de áreas do conhecimento em unidades de informação. 2011. 112f. Trabalho de Conclusão de Curso (Graduação em Biblioteconomia) Universidade Estadual de Londrina, Londrina.

RODRIGUES, M. R.; CERVANTES, B. M. N.. Os mapas conceituais para a visualização de conceitos de áreas do conhecimento em unidades de informação. Revista ACB: Biblioteconomia em Santa Catarina, Florianópolis, v. 18, n. 1 , p. 752-776, jan./jun., 2013. Disponível em: <http://www.revista.acbsc.org.br/racb/article/view/877/pdf>. Acesso em: 5 mar. 2013.

ROVIRA, C. DigiDocMap conceptual maps editor and topic maps norms. Hipertext.net, n. 3, 2005. Disponível em: <http://www.hipertext.net>. Acesso em: 31 jan. 2011.

SOUZA, N. A. de; BORUCHOVITCH, E. Mapas conceituais e avaliação formativa: tecendo aproximações. Educação e Pesquisa, São Paulo, v. 36, n. 3, p. 795-810, set./dez. 2010a.

SOUZA, N. A. de; BORUCHOVITCH, E. Mapas conceituais: estratégia de ensino/aprendizagem e ferramenta avaliativa. Educação em Revista, Belo Horizonte, v. 26, n. 3, p. 195-218, dez. 2010b.

TAVARES, R. Construindo mapas conceituais. Ciências \& Cognição, Rio de Janeiro. v. 12, p. 72-85, out/dez. 2007.Disponível em: <http://www.cienciasecognicao.org/pdf/v12/m347187.pdf>. Acesso em: 5 set. 2012. 